\section{Should Medical Cannabis Administered by Inhalation Be Allowed for Hospitalized Patients?}

\section{THE "PRO" SIDE}

Cannabis has been used medically by many cultures throughout human history. ${ }^{1}$ The origins of cannabis prohibition in Canada began mysteriously in 1923. Legislation was passed swiftly by the House of Commons and the Senate, without any debate, discussion, or presentation of supporting evidence warranting prohibition, and despite a strong historical precedent indicating that cannabis was useful for a variety of ailments. ${ }^{2}$

Today's legal landscape regarding cannabis is evolving quickly, driven primarily by grassroots efforts that recognize the medical value of cannabis, as well as the harms of propagating a drug war against its users. ${ }^{3}$ The problematic consequences of prohibition have been extensive, and review of them in their entirety is outside this article's scope. For the purposes of this article, however, it is worth mentioning one consequence that is cited by the medical community as an adequate reason for continuing prohibitive policy approaches, and that is the lack of clinical data. ${ }^{4}$

For example, the Canadian Medical Association has recommended against the prescribing of medical cannabis, ${ }^{5}$ and cannabinoid prescribing guidelines for Canadian family physicians similarly recommend against prescribing (outside a small subset of conditions refractory to other treatments) because of a lack of high-quality evidence. ${ }^{6}$ Furthermore, although Canadian regulations allow the prescribing of medical cannabis, Health Canada has not approved it for therapeutic use for the aforementioned reason. This logic is circular and flawed, because cannabis prohibition predates the era of evidence-based medicine, and the status of prohibition itself is not evidence-based. Additionally, prohibition has directly oppressed and stigmatized medical research involving cannabis, thus lowering the chances that evidence gaps can be filled. However, recent trials have clearly demonstrated the medical utility of inhaled cannabis, especially for chronic pain. ${ }^{7-17}$ Meanwhile, there are epidemic harms associated with opioid use for chronic pain, which serve to highlight the relatively favourable safety profile of cannabis. ${ }^{4}$

Cannabis is bioavailable by a number of routes, although about two-thirds of patients prefer administration by inhalation (as either vapour or smoke) over other routes, such as oral administration. ${ }^{18}$ Inhalation reduces the latency to onset of action relative to other routes of administration, so patients have faster relief of symptoms and increased control over dose titration. ${ }^{18}$ Reduced latency also increases the hedonic value (pleasurable effect) of the experience and subsequent abuse potential. However, the abuse potential of inhaled cannabis must be interpreted in the context of the abuse potential and safety risks of likely medical alternatives.

Currently, the strongest evidence base for use of cannabis exists for chronic pain syndromes, ${ }^{17}$ which are often present in hospitalized patients. Opioids have been the gold standard for treatment of severe pain in acute care settings, and extension of this practice to patients with chronic noncancer pain has led to epidemic morbidity and mortality in North America. ${ }^{19,20}$ In hospitals, opioids are frequently administered by the IV route, which has a latency of onset similar to that of inhalation (<10 seconds), although it has additional risks, including systemic infection and extravasation. IV administration of opioids also carries significant risks for acute toxicity, including respiratory depression and death, as well as the potential for severe physical and psychological dependence. Additional side effects include constipation, pruritus, sedation, nausea, and vomiting. ${ }^{21}$ Therefore, on the basis of current practice trends, the increased abuse potential associated with administration routes with a decreased latency of onset has been insufficient to prohibit utilization of other substances with medical utility and abuse potential, such as opioids. That being the case, it is unconvincing to disallow use of inhaled cannabis because of the abuse potential associated with the inhaled route of administration.

Additionally, there is an emerging evidence base supporting certain benefits of cannabis, specifically that it can have opioid-sparing effects, can act as an opioid substitute, and can potentially decrease morbidity and mortality related to opioid use, which together may signal inhaled cannabis as an important medical progression in the care of patients with pain. ${ }^{22-25}$ Although the strongest evidence base for cannabis use relates to chronic pain, its effects are myriad and may also decrease the need for other pharmacotherapies. For example, inhaled cannabis can increase appetite, increase the quality and duration of sleep, and decrease nausea, and many patients are using it for mood disorders. ${ }^{26-28}$ These effects offer a multitude of potential benefits to hospitalized patients, especially those receiving palliative care. ${ }^{29}$ 
The significant pharmacokinetic advantages of cannabis delivered by inhalation, evidence supporting patients' preference for inhaled cannabis, and possible clinical advantages over various medical alternatives should naturally lead to extension of its availability to hospitalized patients who are already using medical cannabis. In fact, doing so would be in accordance with best practices for care transitions and compassionate patient-centred care. Each medication that patients use on an outpatient basis should be evaluated by admitting clinicians for appropriateness of continuation upon transfer to the acute care setting. In recent years, there has been a focus on the improvement of medication reconciliation and transitions of care, which has encouraged providers to not abruptly stop or drastically change a patient's medication regimen upon inpatient admission, unless there is a medical rationale for doing so. Negative outcomes associated with poor transitions of care are well documented, and there is no evidence to suggest that medical cannabis should be handled any differently. ${ }^{30}$

There are a number of barriers to implementation of inhaled cannabis in hospitals, as well as unanswered questions about its use, that necessitate flexibility and further study. For example, it appears that vapourization can largely mitigate the risks associated with combustion and the respiratory consequences of smoke inhalation. Potential downsides for other patients or staff in close proximity to cannabis vapour are largely unknown, although they are likely different from those associated with tobacco vapour, given the stark differences in toxicities between the substances. Increasing a building's ventilation and limiting the use of inhaled cannabis to hospitalized patients who can access outdoor or courtyard spaces are potential solutions consistent with current smoking laws. ${ }^{31}$

It is apparent that the medical use of cannabis has been reclaimed by patients and will likely continue to expand in coming years, through both legalization and reduction of stigma associated with cannabis use. Further delaying access to treatment with a therapeutic entity that has been in existence for millennia, that is supported by scientific and public health evidence, and that is widely touted as safe and effective by its users is not compassionate, patient-centred, or evidence-based. In short, it hurts our patients to perpetuate a draconian status quo that prohibits use of cannabis by inhalation. It is time to embrace the medical utility of cannabis fully and in earnest. Barriers and challenges to implementation exist, but they do not represent an adequate rationale for continuing the prohibition of safe and effective treatments involving the inhalation of cannabis inside hospitals.

\section{References}

1. Li HL. An archaeological and historical account of cannabis in China. Econ Bot. 1973;28(4):437-48.

2. Rojek DG. [Book review.] Am J Sociol. 1993;99(2):521-2. Review of: Giffen PJ, Endicott S, Lambert S. Panic and Indifference: The Politics of Canada's Drug Laws. Ottawa (ON): Canadian Centre on Substance Abuse; 1991.

3. Hughes B, Wiessing L, Des Jarlais D, Griffiths P. Could cannabis liberalisation lead to wider changes in drug policies and outcomes? Int J Drug Policy. 2018;51:156-9.
4. Lake S, Kerr T, Montaner J. Prescribing medical cannabis in Canada: Are we being too cautious? Can J Public Health. 2015;106(5):e328-30.

5. CMA policy: medical marijuana. Ottawa (ON): Canadian Medical Association; 2011 [cited 2018 May 3]. Available from: https://www.cma.ca/Assets/assetslibrary/document/en/advocacy/PD11-02-e.pdf

6. Allan GM, Ramji J, Perry D, Ton J, Beahm NP, Crisp N, et al. Simplified guideline for prescribing medical cannabinoids in primary care. Can Fam Physician. 2018;64(2):111-20.

7. Abrams DI, Jay CA, Shade SB, Vizoso H, Reda H, Press S, et al. Cannabis in painful HIV-associated sensory neuropathy: a randomized placebocontrolled trial. Neurology. 2007;68(7):515-21.

8. Corey-Bloom J, Wolfson T, Gamst A, Jin S, Marcotte TD, Bentley H, et al. Smoked cannabis for spasticity in multiple sclerosis: a randomized, placebocontrolled trial. CMAJ. 2012;184(10):1143-50.

9. Ellis RJ, Toperoff W, Vaida F, van den Brande G, Gonzels J, Gouaux B, et al. Smoked medicinal cannabis for neuropathic pain in HIV: a randomized, crossover clinical trial. Neuropsychopharmacology. 2009;34(3):672-80.

10. Haney M, Gunderson EW, Rabkin J, Hart CL, Vosburg SK, Comer S, et al. Dronabinol and marijuana in HIV-positive marijuana smokers: caloric intake, mood, and sleep. J Acquired Immune Defic Syndr. 2007;45(5):545-54.

11. Lahat A, Lang A, Ben-Horin S. Impact of cannabis treatment on the quality of life, weight and clinical disease activity in inflammatory bowel disease patients: a pilot prospective study. Digestion. 2012;85(1):1-8.

12. Wallace MS, Marcotte TD, Umlauf A, Gouaux B, Atkinson JH. Efficacy of inhaled cannabis on painful diabetic neuropathy. J Pain. 2015;16:616-27.

13. Ware MA, Wang T, Shapiro S, Robinson A, Ducruet T, Huynh T, et al. Smoked cannabis for chronic neuropathic pain: a randomized controlled trial. CMAJ. 2010;182(14):E694-701.

14. Wilsey B, Marcotte T, Deutsch R, Gouaux B, Sakai S, Donaghe H. Low-dose vaporized cannabis significantly improves neuropathic pain. J Pain. 2013;14(2):136-48

15. Wilsey B, Marcotte T, Tsodikov A, Millman J, Bentley H, Gouaux B, et al. A randomized, placebo-controlled, crossover trial of cannabis cigarettes in neuropathic pain. J Pain. 2008;9(6):506-21.

16. Wilsey B, Marcotte TD, Deutsch R, Zhao H, Prasad H, Phan A. An exploratory human laboratory experiment evaluating vaporized cannabis in the treatment of neuropathic pain from spinal cord injury and disease.J Pain. 2016; 17(9):982-1000.

17. Whiting PF, Wolff RF, Deshpande S, Di Nisio M, Duffy S, Hernandez AV, et al. Cannabinoids for medical use: a systematic review and meta-analysis. JAMA. 2015;313(24):2456-73

18. Shiplo S, Asbridge M, Leatherdale ST, Hammond D. Medical cannabis use in Canada: vapourization and modes of delivery. Harm Reduct J. 2016;13:30.

19. Rudd RA, Seth P, David F, Scholl L. Increases in drug and opioid-involved overdose deaths-United States, 2010-2015. MMWR Morb Mortal Wkly Rep. 2016;65(50-51):1445-52.

20. Roy G. Opioid-related overdose figures show grim reality of Canadian epidemic. Globe and Mail. 2017 Sep 14 [cited 2018 Jan 30]. Available from: https://beta.theglobeandmail.com/news/national/opioid-related-overdosefigures-show-grim-reality-of-canadian-epidemic/article36257932/?ref=http:// www.theglobeandmail.com\&

21. Schug SA, Zech D, Grond S. Adverse effects of systemic opioid analgesics. Drug Saf. 1992;7(3):200-13.

22. Abrams DI, Couey P, Shade SB, Kelly ME, Benowitz NL. Cannabinoidopioid interaction in chronic pain. Clin Pharmacol Ther. 2011;90(6):844-51.

23. Bachhuber MA, Saloner B, Cunningham CO, Barry CL. Medical cannabis laws and opioid analgesic overdose mortality in the United States, 19992010. JAMA Intern Med. 2014;174(10):1668-73.

24. Elikottil J, Gupta P, Gupta K. The analgesic potential of cannabinoids. J Opioid Manage. 2009;5(6):341-57.

25. Reiman A, Welty M, Solomon P. Cannabis as a substitute for opioid-based pain medication: patient self-report. Cannabis Cannabinoid Res. 2017;2(1): 160-6.

26. Bradford AC, Bradford WD. Medical marijuana laws reduce prescription medication use in Medicare Part D. Health Aff(Millwood). 2016;35(7):1230-6.

27. Stith SS, Vigil JM, Adams IM, Reeve AP. Effects of legal access to cannabis on scheduled II-V drug prescriptions. J Am Med Dir Assoc. 2018;19(1): 59-64.e1. 
28. Park JY, Wu LT. Prevalence, reasons, perceived effects, and correlates of medical marijuana use: a review. Drug Alcohol Depend. 2017;177:1-13.

29. McCarberg BH. Cannabinoids: their role in pain and palliation. J Pain Palliat Care Pharmacother. 2007;21(3):19-28.

30. Snow V, Beck D, Budnitz T, Miller DC, Potter J, Wears RL, et al. Transitions of care consensus policy statement American College of Physicians-Society of General Internal Medicine-Society of Hospital Medicine-American Geriatrics Society-American College of Emergency Physicians-Society of Academic Emergency Medicine. J Gen Intern Med. 2009;24(8):971-6.

31. Holitzki H, Dowsett LE, Spackman E, Noseworthy T, Clement F. Health effects of exposure to second-and third-hand marijuana smoke: a systematic review. CMAJ Open. 2017;5(4):E814-22.

Benjamin J Malcolm, PharmD, MPH

Assistant Professor of Pharmacy Practice

College of Pharmacy

Western University of Health Sciences

Pomona, California

Competing interests: None declared.

\section{THE "CON" SIDE}

Although inhaled cannabis is proposed to have benefits as an analgesic, antispasmodic, anticonvulsant, antinauseant, and appetite stimulant, Health Canada has not reviewed data on its safety or effectiveness and has not approved cannabis for therapeutic use. ${ }^{1,2}$ Few studies have examined the effects of inhaled cannabis, and the benefits of smoked or vapourized cannabis, based on low- or moderate-quality evidence, have been described only for neuropathic pain and spasticity. 2,3

Despite the paucity of evidence, Canadian regulations on cannabis for medical purposes permit the authorization of cannabis for patients, who can then purchase it directly from licensed producers. ${ }^{4}$ When outpatients who have been using cannabis for medical purposes are admitted to hospital and want to continue their therapy through inhaled delivery routes, there are significant implications for the hospitals. Relevant legislation, quality control, and safety for patients and their families, as well as for hospital staff, are important considerations as hospitals develop policies and procedures to address the use of inhaled cannabis.

Cannabis can be delivered orally, by inhalation, or intranasally. A 2015 survey of adult Canadian medical cannabis users $(n=364)$ reported smoking as the preferred mode of delivery (37.6\%), followed by vapourizing $(28.3 \%)$ and eating in foods $(7.1 \%) .{ }^{1}$ The more recent 2017 Canadian Cannabis Survey found that among respondents using cannabis for medical purposes ( $n=1105), 81 \%$ reported using dried flower or leaf products (likely smoked or vapourized), and 30\% reported using edible products. ${ }^{5}$ The advantages of smoking cannabis, as reported by users, include greater enjoyment, greater convenience, more immediate and effective relief of symptoms, and whole-body euphoria. ${ }^{1}$ The considerable disadvantages of smoking include increased potential for abuse because of the fast onset, ${ }^{6}$ health risks from smoke inhalation (e.g., cancer, emphysema, bronchitis, cough, sputum production, wheezing), ${ }^{7}$ and the formation of toxins at the time of combustion, as well as social disapproval of smoking and the associated smell. ${ }^{1}$

Because of the health risks related to smoking, Canada became a party nation to the World Health Organization Framework Convention on Tobacco Control $^{8}$ in 2005. This treaty was developed to protect the public's health from the harm caused by tobacco smoke. In Canada, participation in this treaty led to the development of provincial and territorial legislation to ban smoking in many public spaces and workplaces, including hospitals. ${ }^{9}$ Although each province and territory developed its legislation independently, there is overall consistency across jurisdictions, with some variations, including the distance from a building entrance at which an individual can smoke or whether smoking is permitted inside a vehicle that is carrying children. In most jurisdictions, smoking of cannabis is not explicitly banned by the legislation; however, New Brunswick and Nova Scotia are adding cannabis to their respective Smoke-free Places Acts. ${ }^{10,11}$ These changes mean that provincial health authorities are concerned about the harm that smoking of cannabis poses for the public, much like the smoking of tobacco. Other provinces and territories will likely follow suit to extend the principle of protecting public safety in and around hospitals from not just tobacco, but also cannabis. Vapourization of tobacco is subject to the same smoking regulations in each province, and is not allowed inside many workplaces, including hospitals. ${ }^{12}$

Vapourization of cannabis delivers inhaled tetrahydrocannabinol and other cannabinoids by heating either dry herb (raw plant product) or oil in a non-portable plug-in machine or a portable device. Vapourizing cannabis has been proposed as a harm reduction strategy because without the combustion that occurs with smoking, there is a decrease in toxic byproducts and lower concentrations of exhaled carbon dioxide. ${ }^{2,13}$ The 2015 survey of adult Canadian medical cannabis users found that those vapourizing cannabis most frequently used the portable devices. ${ }^{1}$ Although overheating can occur with any device, portable devices generally have an increased risk of this problem, and the overheating can lead to some combustion of the product, especially when dry herb is used. ${ }^{1}$ This risk would negate any safety benefits of vapourization over smoking. Cannabis vapour produces pharmacokinetic effects similar to those of cannabis smoke, resulting in turn in a similar risk of abuse related to the rapid onset. ${ }^{5,13}$ The unique disadvantages of vapourizing include the cost of devices to patients and the difficulty of operating them; for example, some devices require the user to capture the vapour in a bag, then inhale it, whereas other devices use a breathing wand.

Although vapourizing is likely less harmful than smoking, ${ }^{7}$ there is still significant risk of vapour escaping into the environment. This vapour may expose hospital staff and neighbouring patients or families to the product. It has a strong scent, yet the hospital setting is an environment where many people may be sensitive to scent, and many hospitals have scent-free policies. In hospitals that use an optical sensor 
to detect smoke in the environment, the escape of large amounts of vapour (e.g., through user error or device failure) could conceivably falsely trigger an alarm. The process of administering cannabis to the patient may also present a challenge. If patients are unable to set up the devices themselves or to self-administer the vapourized product, there could be an expectation that hospital staff will support administration using expensive and sometime complex devices, in the absence of industry standards. Hospitals must also consider the large energy requirement of vapourizers, up to $700 \mathrm{~W}$. Devices would likely require assessment by the organization's fire safety group, because these high energy requirements might translate into risks to fuses or breaker issues if the required energy is not properly supplied.

Regardless of the delivery system, there remains controversy over the quality control of cannabis products. ${ }^{14}$ Therapeutic management in the hospital setting is complicated, since without a biochemical analysis using verified phytocannabinoid standards, patients and health care providers are unable to identify the composition or consistency of the product. ${ }^{14}$

In summary, the inhaled route of administration of cannabis for medical purposes is associated with risks for patients, families, hospital staff, and others in the environment. There are also legislative and operational issues related to smoking and vapourizer devices that hospital administrators would have to consider. From a clinical perspective, pharmaceutical cannabinoids should be considered before cannabis for patients who need this type of therapy. ${ }^{2}$ Therefore, cannabis for medical purposes should not be administered by inhalation to hospitalized patients. Other routes of administration, such as the oral route, may be considered by institutions as preferred alternatives.

\section{References}

1. Shiplo S, Asbridge M, Leatherdale ST, Hammond D. Medical cannabis use in Canada: vapourization and modes of delivery. Harm Reduct J. 2016; 13(1):30.

2. Kahan M, Srivastava A, Spithoff S, Bromley L. Prescribing smoked cannabis for chronic noncancer pain: preliminary recommendations. Can Fam Physician. 2014;60(12):1083-90.

3. Whiting PF, Wolff RF, Deshpande S, Di Nisio M, Duffy S, Hernandez AV, et al. Cannabinoids for medical use: a systematic review and meta-analysis. JAMA. 2015;313(24):2456-73. Errata in: JAMA. 2016;315(14):1522; JAMA. 2015;314(21):2308; JAMA. 2015;314(5):520; JAMA. 2015; 314(8):837.
4. Marihuana for Medical Purposes regulations. Canada Gazette Part 1. 2012; 146(50):3422-536.

5. Theme 4: Cannabis for medical purposes. In: Canadian cannabis survey 2017 - summary. Ottawa (ON): Health Canada; 2017 [cited 2018 May 10]. Available from: https://www.canada.ca/en/health-canada/services/publications/ drugs-health-products/canadian-cannabis-survey-2017-summary.html\#a4

6. Samaha AN, Robinson TE. Why does the rapid delivery of drugs to the brain promote addiction? Trends Pharmacol Sci. 2005;26(2);82-7.

7. Loflin M, Earleywine M. No smoke, no fire: what the initial literature suggests regarding vapourized cannabis and respiratory risk. Can J Respir Ther. $2015 ; 51(1): 7-9$.

8. WHO framework convention on tobacco control. Geneva (Switzerland): World Health Organization; 2003 [cited 2017 Oct 2]. Available from: http://apps.who.int/iris/bitstream/10665/42811/1/9241591013.pdf?ua=1

9. Smoke Free Ontario Act, S.O. 1994, c. 10 [cited 2017 Oct 2]. Available from: https://www.ontario.ca/laws/statute/94t10

10. Amendments introduced to the Smoke-free Places Act [news release]. Fredericton (NB): Government of New Brunswick, Health; 2016 Nov 17 [cited 2018 May 10]. Available from: http://www2.gnb.ca/content/gnb/en/ news/news_release.2016.11.1121.html

11. Cannabis legalization. Halifax (NS): Province of Nova Scotia; [cited 2018 May 10]. Available from: https://novascotia.ca/cannabis/

12. Huh NY. Vaping and e-cigarette regulations across Canada. CBC News. 2016 Oct 19 [cited 2017 Oct 2]. Available from: www.cbc.ca/news/canada/ vaping-regulations-1.3812180

13. Abrams DI, Vizoso HP, Shade SB, Jay C, Kelly ME, Benowitz NL. Vaporization as a smokeless cannabis delivery system: a pilot study. Clin Pharmacol Ther. 2007;82(5):572-8.

14. Russo EB. Current therapeutic cannabis controversies and clinical trial design issues. Front Pharmacol. 2016;7:Article 309.
Laura Murphy, BSCPhm, ACPR, PharmD

Department of Pharmacy, Toronto Rehabilitation Institute University Health Network

Toronto, Ontario

Michael Wong, BScPhm, ACPR

Department of Pharmacy, Toronto General Hospital/

Toronto Western Hospital

University Health Network

Toronto, Ontario

Competing interests: None declared. 